\title{
Lazer, educação e políticas públicas em países emergentes: reflexões sobre o caso brasileiro.
}

\author{
Leisure, education and public policy in emerging \\ countries: reflections on the case Brazilian.
}

\author{
Loisirs, education et politiques publiques dans les \\ pays emergents: réflexions sur le cas du brésil.
}

\author{
José Carlos de Almeida MORENO \\ Luciene Ferreira da SILVA
}

\begin{abstract}
RESUMO
A problemática abordada neste artigo, diz respeito à não eficácia de políticas setoriais atuantes na Educação de crianças, adolescentes e jovens brasileiros, sobretudo os de classe mais desfavorecida. Sustenta-se a tese de que políticas setoriais de lazer e Educação podem instaurar um movimento educacional crítico e emancipatório, quando focam o indivíduo, a sua essência humana e a vida enquanto instância superior e primeira, ultrapassando elementos como a mercantilização e chegando ao "imercantilizável". O objetivo foi refletir, analisando as possibilidades de proposição de saltos qualitativos na Educação, através da ampliação das políticas setoriais, abordando a de lazer, como de suma importância para o processo de desenvolvimento humano. Partiu-se do pressuposto que as camadas mais favorecidas economicamente possuam, por conta do seu lócus social, mais oportunidades de formação com o lazer, mas nem estas, estão salvaguardadas, se socialmente não lhes forem garantidas legislativamente, o tempo para serem crianças, adolescentes, jovens e adultos. E nem, de usufruírem o lazer no tempo-livre, se o trabalho for o único objetivo a ser alçado ou ainda, se o lazer proporcionado for do tipo "mercadoria". O artigo resgata a necessidade de Educação para formação da pessoa, para a liberdade, fazendo escolhas por caminhos "vistos". Buscou superar a visão clássica de desenvolvimento educacional via modelos "intra muros" das escolas brasileiras, e que não se resolvem sem que haja alteração do panorama político e econômico. Alerta para a necessidade de adaptações do sistema socioeconômico para a vida do homem e não de adaptação do homem a este, o que tem gerado desequilíbrio entre as nações e na homeostase, via políticas públicas setoriais, gestadas a partir de um "todo" bem estruturado. Conclui-se que estudos sociológicos, educacionais e culturais sobre o lazer, a Educação e as políticas públicas são significativos quando abordados conjuntamente.
\end{abstract}


Palavras Chave: Educação, Lazer, Políticas Públicas Setoriais.

\begin{abstract}
The problematic that is approached in this paper concerns about the lack of effectiveness of non-sectorial policies that act with the education of children, adolescents and young Brazilians, especially the ones from the most disadvantaged social class. It sustains the thesis that political sector of leisure and education may introduce a critical and emancipatory educational movement, when focusing on the individual, on his human essence and life as a superior and first instance, surpassing elements such as merchandising and reaching the not-merchandising. The aim was to reflect, examining the possibilities of proposals for qualitative leaps in Education, through the expansion of sectorial policies, approaching that of leisure in its paramount importance to the process of human and social development. It was assumed that the most economically advantaged class have, on account of their social locus, more training opportunities with the leisure, but neither they are safeguarded, if socially they are not guaranteed legislatively, the time to be children, adolescents and young adults. Nor from enjoying the leisure of free time if the work to be the only objective being reached or if the entertainment to be provided for the "goods". The article recalls the need for Education for formation of the person, for freedom, making choices for observed paths. It searched to overcome the classical vision of development through educational models "behind walls" of Brazilian schools, and that can not be resolved without any change of political and economic landscape. It alerts to the need of adjustments to the socio-economical system for the life of man and not the man to adapt to this, which has created imbalance-between nations and homeostasis through sectorial public policies proposed from a "whole" well-structured. It follows that sociological studies, educational and cultural on leisure, education and public policies are significant when addressed together.
\end{abstract}

Index terms: Education, Leisure, Sectorial Public Policy.

\title{
RÉSUMÉ
}

La problématique qui est abordée dans ce document concerne le manque d'efficacité des politiques de non-sectoriels qui agissent avec l'éducation des enfants, des adolescents et des jeunes Brésiliens, en particulier ceux des plus défavorisés. Il est dit, la thèse selon laquelle le secteur politique des loisirs et l'éducation mai présenter une motion critiques d'éducation et d'émancipation, lorsqu'on se concentre sur l'individu, son 
essence et la vie humaine comme un des éléments supérieur et le premier, dépassant tels que le marchandisage et a atteint le Non - merchandising. L'objectif était de réfléchir, d'examiner les possibilités de propositions de sauts qualitatifs en matière d'éducation, par l'expansion des politiques sectorielles, s'est rapproché de celui des loisirs, comme d'une importance primordiale pour le processus de développement humain et social. On a supposé que les plus économiquement favorisés ont, à cause de leur lieu social, plus d'opportunités de formation avec le loisir, mais ni eux, sont protégés, socialement si elles ne sont pas garantis plan législatif, le temps d'être des enfants, adolescents et jeunes adultes . Ni, de jouir des loisirs de temps - libre, si le travail est le seul objectif étant d'élévation ou, si le divertissement prévues pour les "marchandises". L'article rappelle la nécessité d'une éducation pour la formation de la personne, à la liberté, faire des choix pour les chemins observés. Il a cherché à surmonter la vision classique du développement grâce à des modèles éducatifs "derrière les murs» des écoles brésiliennes, et qui né peut être résolue sans un changement du paysage politique et économique. Alerte à la nécessité d'ajustements du système socio-économique pour la vie de l'homme et non l'homme pour s'adapter à ce qui a créé un déséquilibre entre les nations et de l'homéostasie par des politiques publiques sectorielles, proposé à partir d'un «tout» bien structurés. Il s'ensuit que les études sociologiques, éducatifs et culturels sur les loisirs, l'éducation et les politiques publiques sont importantes quand traitées ensemble.

Mots-clés: Éducation, du Loisir, Politique publique de section.

\section{1- AMPLIANDO O FOCO: SOCIEDADE, LAZER E EDUCAÇÃO.}

A Educação tem se constituído em desafio para países pobres e em desenvolvimento tendo em vista as condições de desigualdades socioculturais e de distribuição de renda que cada um deles possui. No Brasil, por exemplo, configura-se uma situação persistente em que há escolas públicas voltadas para as classes desfavorecidas e há escolas privadas que atendem aqueles que podem pagar. Isso é bem evidente em todos os níveis de ensino. No Ensino Superior há a retirada maciça do poder público do cumprimento do oferecimento de Educação Superior para as camadas populares e estas só chegam a este nível de ensino mediante a 
conciliação entre trabalho e estudos. São trabalhadores que estudam no período noturno em sua maioria e se formam para o trabalho, em geral, para assumirem funções técnicas ou braçais.

As condições de ascensão da população atendida pela escola pública brasileira na Educação Básica são desfavoráveis e quando ocorre está atrelada muito mais a méritos pessoais ligados a história dos sujeitos. Mas, o caminho de direito, dar-se-ia a partir do acesso a uma Educação de qualidade e este fica dificultado quando se tem condição muito restrita, de desenvolvimento humano e cultural.

Neste artigo, a tese que se defende é a de que o aluno da classe trabalhadora está oprimido e que esta situação se deve ao que Fromm (1963), na obra Psicanálise da sociedade contemporânea, considerou como um estado de "insanidade" em que o ser humano na sociedade ocidental contemporânea se encontra por causa do desajuste da pessoa ao sistema.

Para o autor, há uma ausência de saúde em decorrência das tentativas do ser humano tentar se adequar à sociedade, quando considera que o ideal para a saúde seria a sociedade atender às necessidades do homem.

Depreende-se que, além disso, ocorrendo, em todos os setores da vida social, há um grande controle do tempo e de uso deste para uma produção "esvaziada", de bens e produtos, para o capitalista Quando se diz "esvaziada" se quer dizer da forma contrária ao trabalho que se concretiza como expressão e realização humana.

No Brasil, vive-se em meio a uma distribuição muito desproporcional de riqueza entre os que possuem o capital e os que só são utilizados em sua força de trabalho e são por isso, assalariados e direcionados para certas tarefas, serviços e trabalhos que os levam a uma situação de opressão, bem como de suas famílias. Aqui, especialmente, interessa-nos os estudantes que compõem essa grande massa de "estudantes - trabalhadores", oprimidos que não têm tempo - livre ou disponível que 
para Marcellino (2002) é aquele possível de materialização do lazer e que para Dumazedier (1980) é:

\begin{abstract}
“...um conjunto de ocupações as quais o indivíduo pode entregar-se de livre vontade, seja para repousar, seja para divertir-se, recrear-se e entreter-se ou, ainda para desenvolver sua informação ou formação desinteressada, sua participação social voluntária ou sua livre capacidade criadora após livrar-se ou desembaraçar-se das obrigações profissionais, familiares e sociais" (p.21).
\end{abstract}

Então, sua Educação empobrecida no Ensino Fundamental, reduziuse ainda mais na Educação Superior às horas nos bancos escolares dos cursos, não sobrando outras formas de formação que permita um processo de desalienação e Edúcação para a vida e a liberdade. Quando escrevemos outras formas estamos nos referindo à educação extra-escolar proporcionada também pelo lazer, quando propicia desenvolvimento, descanso e divertimento (cf. DUMAZEDIER, 1980).

Fromm (1963) designa este ser como aquele que "se sente" uma criatura pequena que corre da "grande criatura", que o ameaça. O ser humano compete na sociedade capitalista e se sente só e impotente. O autor desenvolveu suas teses num momento em que aumentavam os sintomas de doenças; homicídios, suicídios e alcoolismo nos Estados Unidos, na década de cinqüenta.

Ele chamou de "segundo nascimento do homem" quando este adquire consciência de si e do outro e daí a capacidade de amar a si e ao próximo. Tal condição o liberta do comportamento egoísta gerado pela sociedade capitalista. Fromm (1963) utilizou o termo "relações fraternas" como uma potencialidade para a saúde, na sociedade ocidental contemporânea.

$\mathrm{Na}$ atualidade, observa-se que o lazer tem se constituído em "válvula de escape" como especificaremos a seguir e que só uma educação para o lazer poderá contribuir para uma compreensão mais aprofundada da lógica 
de consumo que está imbuída também nessa esfera. Ou seja, aqui o lazer / visto como possibilitador, entre outras coisas das "relações fraternas" citadas por Fromm (1963).

\section{2- LAZER, SAÚDE E EDUCAÇÃO: O ENFOQUE.}

A obra de Fromm (1963) é elucidativa neste sentido, quando este autor expõe que a alienação está em todas as partes e que na sociedade capitalista o prazer "de posse" não se concilia com o "prazer de uso", sendo a "posse inútil", pois estaria atrelada a idéia de consumir e não ao produto em si. Tal alerta já era feito pelo autor quando estudou o papel da publicidade, na década de cinqüenta.

$\mathrm{Na}$ atualidade, o consumo de algo que "deveria" satisfazer por si só, está sendo substituído pelo prazer de consumir unicamente. E, nesse sentido, o lazer para Fromm (1963) também é consumível, não é vivenciado participativamente, pois seu consumo está determinado pela indústria e se constitui em mais uma "válvula de escape".

Fromm (1963) aborda as relações de interesses neste tipo de sociedade, atrelando as leis de mercado que também são alienadas e afirma que as pessoas estão juntas por interesse, inclusive nas relações amorosas.

Isso-posto, e juntados outros fatores como a rotinização proporcionada pela alienação e vice-versa, temos o funcionamento da lógica das "operações de troca". Tudo se opera na troca.

O lazer então, para Fromm (1963), também é medido em tempo e dinheiro e a vida a ser encarada como empreendimento comercial, proporcionando tédio e doenças.

Esse processo ficaria aliviado mediante as terapias e pelo próprio lazer em si, que fazem ou que poderiam desempenhar papéis compensatórios, de alívio imediato ou em curto prazo, para que o homem oprimido suporte a insatisfação, tédio e as doenças ocasionadas por questões 
de fundo existencial e social. Aliviar para "agüentar" mais. Fuga da reflexão crítica, para modificação do que não agrada ou não suporta. Nesse sentido, conclui o citado autor que religião, lazer e psicanálise são formas de "analgesia" no meio social.

No Brasil, "O tempo de não-trabalho nos moldes das Constituições de 1934 e 1937, assim como pela CLT de 1943, é compreendido como sobra do tempo social considerado útil (o do trabalho). O tempo é aí valorizado como recompensa do trabalho ou redenção dos problemas sociais, e não como direito, necessidade e vontade coletivas". (PINTO, 2008, p. 82).

Assim, para a autora, naquele período, o assistencialismo se materializou por meio da recreação, considerada como prática ou atividjade orientada tendo sempre a presença de "um doador" e um "receptor". Tais atividades tinham como objetivo recompor a força de trabalho. De certa forma, assumindo também a forma de analgesia ou de descanso para retomada pacífica das atividades de trabalho, organizadas pelos detentores do capital.

O período de 1960 a 1970 foi de alteração na política social brasileira. Políticas voltadas para a população em geral foram criadas e desenvolvidas. Surgiram as Ruas de Recreio, que se constituíam em atividades esportivas e recreativas em ruas e praças. No Brasil, até hoje, esse modelo é utilizado em políticas públicas municipais. (PINTO, 2008). Ainda neste período se percebia o efeito analgesizante verificado nos períodos anteriores.

Já na década de 80, sem o regime autoritário, com a abertura para participação dos cidadãos, o capitalismo se consolidou e o lazer se sobressaiu como mercado emergente. E, "Gerou expressiva atividade econômica, passando a exigir mão de obra diversificada e qualificada para atender aos novos empreendimentos e demandas". (PINTO, 2008, p. 85).

Este momento coincidiu também com o que Fromm (1963) falou sobre a sociedade, embora não tivesse abordado os modelos comunista ou 
capitalista, anunciou e identificou uma sociedade ligada ao robotismo. Ele colocou perante todos a vida e a morte, cabendo ao ser humano fazer escolhas.

No Brasil, diferentemente dos EUA, o capitalismo mais tardiamente instaurado, perpetuou-se e, na Constituição de 1988, predominou a visão assistencialista do lazer, compreendendo-o como utilidade e não como fator de desenvolvimento humano e social. (PINTO, 2008, apud MARCELLINO, 2001). Pinto (2008) considera que nesta fase, e ainda com restrições, o lazer passou a ser um direito constitucional de todos, não apenas dos trabalhadores e tido como benefício social para a melhoria da qualidade de vida. Por conta disso, novos desafios foram colocados para a sociedade e seus governantes para a garantia do lazer.

Entretanto, a defesa da Educação, do lazer-educação e da educação para o lazer sofreu a partir da década de 90 , com o modelo neoliberal, em que houve transferência dos serviços sociais sob a responsabilidade do governo, para a comunidade. Com isso, Pinto (2008) concluiu existir formas distintas de ver e agir politicamente: uma ligada à acumulação de capital, sem preocupação com os impactos na vida humana, sobretudo dos mais excluídos, e outra voltada para a promoção dos indivíduos e defesa de-seus direitos, produzindo novos sentidos, até então deixados de lado nas relações humanas.

Como educadores que lidam com a cultura, a política e a sociedade, o lazer se colocou e se coloca atualmente, e cada vez mais, como objeto não só de proposições isoladas para a qualidade de vida e o bem-estar social, passando a ser estudado como fenômeno ligado intimamente à Educação, sobretudo, por conta do componente lúdico. As formas tradicionais de abordagem de crianças, adolescentes e jovens não são efetivas para todos os grupos indistintamente.

Ainda, a vinculação dos estudos do lazer de maneira mais acentuada, se dá, por meio de licenciados em Educação Física e Educação Artística 
embora de forma incipiente e teoricamente frágil, haja vista a preponderância de disciplinas curriculares voltadas para a recreação.

Aproveitamos-nos das conclusões de Fromm (1963) para ilustrar a colaboração passível de ser dada pelos educadores em todas as esferas educacionais, pois, para ele, a felicidade é um sentimento de plenitude que pode ocorrer por meio de construções de projetos críticos e criativos, havendo uma superação através do amor, acarretando equilíbrio e saúde. Pensamos que a criticidade, a criatividade e o afeto sejam de fato amplamente necessários aos sujeitos construtores de sociedades emergentes.

\section{3- LAZER, EDUCAÇÃO E POLÍtICAS PÚBLICAS: A POSSIBILIDADE.}

No Brasil, desde a Constituição Federal de 1988, o lazer se constitui em direito de todos os cidadãos. Também as constituições estaduais e leis orgânicas de municípios brasileiros asseguram esse direito. (BRASIL, 2002).

Para Marcellino e Ferreira (2007), embora seja uma "garantia", está situação, por motivos que vão desde a hierarquia da valorizảção historicamente seguida entre as áreas que compreendem a esfera đe gestão pública, até-a cultura sobre a compreensão do lazer, que sé dá mediante a produção científica na área, e o desenvolvimento educacional, econômico e político, não se materializa a contento.

Marcellino (2008), ao estudar o tema políticas públicas de lazer, desenvolveu artigo sobre subsídios para a implementação destas políticas. Para esse renomado pesquisador brasileiro, o lazer tem sido visto enquanto fenômeno reduzido, ao ser abrangido como um de seus conteúdos culturais, descritos por DUMAZEDIER (1980) e que compreendem os interesses manuais, artísticos, intelectuais, físico - esportivos, entre outros. 
Essa tendência restrita, que pode ser constatada na linguagem popular pela simples observação assistemática, é alimentada pelos meios de comunicação de massas na veiculação da programação de atividades, via de regra ligadas ao esporte e à arte, e só mais recentemente distinguindo o lazer, quase sempre associado a manifestações de massa, ao ar livre, com conteúdo recreativo... (MARCELLINO, 2008, p. 11).

Assim, este autor manifesta que o lazer, se reduzindo a um ou mais conteúdos não é compreendido de forma a alcançar amplamente a comunidade, através de políticas públicas municipais, estaduais ou federais, junto à saúde, Educação, desenvolvimento econômico e sócio-cultural, fator de transformações sociais e gerador de qualidade de vida.

Marcellino (2008) constata que o divertimento e o descanso no senso comum são os termos mais atribuídos ao lazer, deixando-se de lado o desenvolvimento pessoal e social. Nesse caso, fica claro que se trata de um fator cultural e como tal, ligado à Educação de maneira geral e mais especificamente à educação para o lazer.

O Brasil, por se constituir num país jovem e em desenvolvimento, bụsca se inserir mundialmente como potência econômica e, ao visualizarmos a Educação brasileira, esta sempre ocorreu paralelả ao desenvolvimento econômico, fazendo da formação para o mundó do trabalho o_seu objetivo precípuo.

Uma sociedade marcada por diversidades socioculturais teve e tem dificuldades na implementação de políticas educacionais com enfoque na formação do ser humano que, entre outras coisas, trabalha e deve se realizar através deste, mas nunca unicamente; e também não deve ter o trabalho enquanto atividade alienante, escravizante e impossibilitadora do usufruto de uma vida que chamaremos de plena ou com liberdade, ou ainda, uma "vida vivida" com consciência.

Pretendendo-se que o lazer não constitua apenas a oportunidade de recuperação da força de trabalho ou que possa ser caracterizado como instância de consumo 
alienado ou "válvula de escape", que ajude a manter o quadro social injusto... (MARCELLINO, 2008, p. 12).

Nesse sentido, Marcellino (2000) considera o duplo aspecto educativo do lazer como objeto e como instrumento, e aqui nos ocorre ser central discutir a Educação enquanto processo muito mais amplo do que aqueles ligados ao acesso aos conhecimentos acumulados, ou à instrumentalização para o mundo do trabalho.

Segundo Marcellino (2008), para o desenvolvimento pessoal e social já abordados aqui, cabe observar a interface necessária com as políticas públicas de Educação, Saúde e Promoção Social, não se restringindo a uma política de atividades, mas a uma política de possibilidades que vai desde os equipamentos de lazer, a distribuição destes, a gestão dos projetos é os profissionais atuantes, que não compactuem com a chamada "indústria cultural", que se manifesta no lazer enquanto mercadoria, mas com outra que ajuda na percepção da realidade vivida.

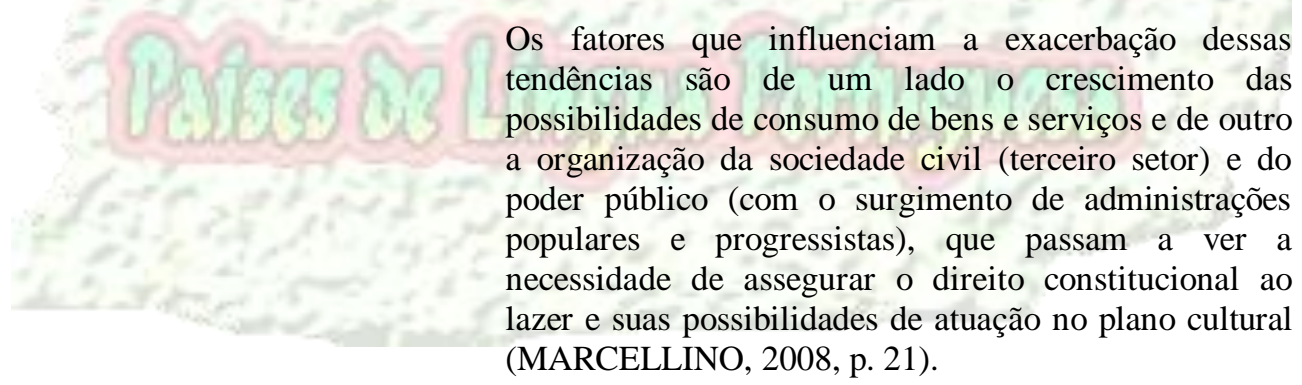

Quando se verifica a realidade brasileira, da maioria das crianças, dos adolescentes e jovens que estão sendo preparados para o trabalho menos valorizado socialmente e que possuem muitas restrições para o lazer, indagamos sobre o acesso que estes tiveram a políticas que priorizassem o lazer direta e indiretamente. Afinal, não é possível estabelecer uma política de lazer não assistencialista, sem fazer parte de um conjunto de políticas, ou de uma política maior de bem estar social e desenvolvimento humano. 
A política educacional não deve ser concebida separada ou independente do lazer, como também não o podem, as políticas econômicas, de saúde e de segurança. No estudo de Marcellino (2008), este revela que sempre houve a necessidade de conexão dessas expressões ao lazer para que este tivesse uma conotação mais aceita socioculturalmente, o que não é mais admissível na atualidade, pois se colabora dessa forma para a disseminação pouca objetiva do conceito ou entendimento do lazer que "ora é serviço, ora departamento, ora setor, ora secretaria, etc., dividindo espaço, ou melhor, sobrepondo espaço, o que é muito mais grave, ora com Educação, Cultura, Turismo, Esporte, Recreação, etc...” (p. 23).

O que se admite é que uma política dé Lazer ou de Educação esteja a serviço do Homem em sua totalidade, atuando em benefício de sua formação para a vida, para os indivíduos e todos os grupos sociais.

... que se percebe hoje é que ganhou vida própria,
independente, uma clara alusão ao entretenimento como
o "lazer mercadoria". Não atividades populares ligadas
à alma da população, mas "popularescas", no sentido de
nivelamento "por baixo", com o único objetivo dé
"desviar" a atenção "de", e esse "de", quase sempre,
pode ser entendido como a triste realidade péssoal e
social dos seres humanos. É a distração, significando
alheamento e não, como propõe o educador Rübem
Alves (1986), "atração por um outro mundo". Um
mundo diferente, de sonho e invenção, de uma
sociedade mais justa, de um ser mais humano.
(MARCELLINO, 2008, p. 24).

Questiona-se que a participação no lazer não resolverá problemas de ordem política e econômica, e que tal ilusão não pode ser disseminada, mas, que o lazer como a Educação são bens sociais que permitem a visualização desse panorama e a tomada de decisão sobre a vida que se quer ter ou o rumo que se quer seguir.

No caso de políticas públicas de lazer, Marcellino (2008) esclarece que há necessidade de uma política integrada entre as secretarias, 
departamentos, ministérios,... "uma vez que o lazer está ligado à Educação, à saúde, à habitação, ao transporte, ao serviço social". (p. 27).

As políticas públicas então, de lazer e Educação, que favoreçam a formação das crianças, adolescentes e jovens brasileiros devem proporcionar a ampliação dos horizontes, melhorar a visibilidade e encher de ânimo, alegria e esperança os indivíduos com uma formação mais completa e mais profunda.

E isso vai desde coisas extremamente simples - como o funcionamento dos serviços de lazer, aos fins de semana, feriado, à noite, ou seja, quando a clientela tem tempo disponível, e não apenas quando o profissional tem tempo para o atendimento entre um e outro emprego, fazendo bicos... (MARCELLINO, 2008, p. 27).

Alerta também o autor de que esta política tem que incluir a oportunidade de discussões dos vários setores sociais, câmaras, sindicatos, entidades de classe, entre outros que podem garantir mais qualidade à proposta para atendimento de crianças e adolescentes.

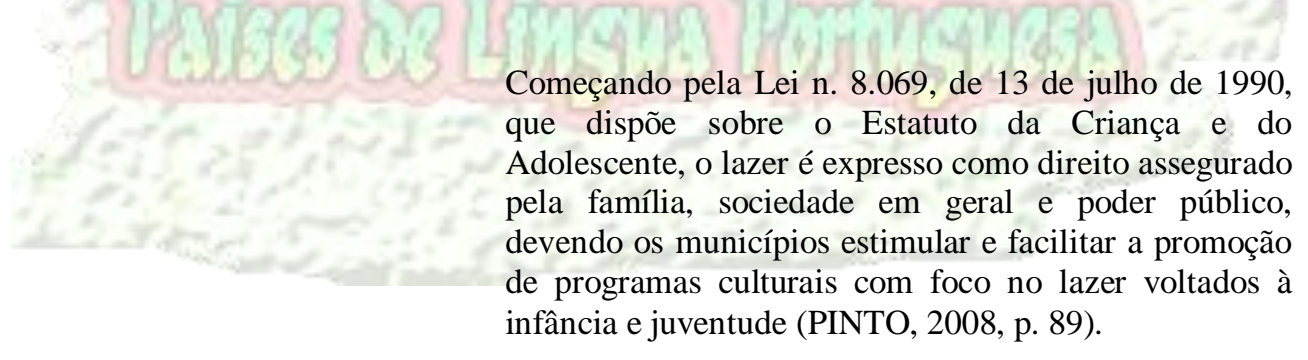

Quanto aos idosos, escreve Pinto (2008) que o Estatuto do Idoso, de 01 de outubro de 2003, prevê estímulo ao lazer visando melhoria da qualidade de vida e a participação comunitária.

Os portadores de transtornos mentais tem direitos garantidos pela Lei n. 8.080 que aborda o lazer como fator de saúde de toda a população e a Lei n. 10.216, em seu art. 4 que "dispõe sobre os direitos das pessoas portadoras de transtornos mentais, destacando o lazer como um serviço obrigatório no tratamento desses, em regime de internação (PINTO, 2008, p. 90). 
Em relação aos Parâmetros Curriculares Nacionais - PCN, 2000, a autora em seu artigo, esclarece que à Educação Física se incumbiu de cuidar da educação corporal..."nela considerando a educação para a participação lúdica no lazer (PINTO, 2008, 90).

Assim, o momento atual que tentamos recuperar se mostra favorável para o desenvolvimento de propostas mais bem alicerçadas e para isso as políticas públicas setoriais são de suma importância.

Marcellino (2008) propõe quatro eixos, pelo menos, para que se desenvolva um trabalho integrado em Políticas Setoriais de Lazer a partir:

- Dos conteúdos culturais (integração do trabalho realizado pelas secretarias / órgãos que lidam com artes, cultura, esporte, meio ambiente, turismo, patrimônio, etc.);

- Dos valores associados ao lazer (que requer integração entre setores, secretarias/órgãos, que extrapolem a questão cultural Educação e Saúde);

- Das barreiras para a sua prática (trabalho integrado das secretarias/órgãos que também extrapolem a questão cultural Promoção Social, Transporte, Parques e Jardins);

Das circunstâncias que o cercam (trabalho que vislumbre a polîtica de reordenação do solo urbano, do tempo e necessidade de relação com o legislativo).

Tais eixos podem ajudar na sustentação da política que se almeja, no entanto, não se deve desconsiderar que toda prática social não acontece linearmente e que obedecem a normas e graus de autonomia conquistados historicamente (PINTO, 2008).

Nesse caso, há forte dependência da esfera onde se farão as propostas de implementações de políticas setoriais que tenham o enfoque assumido ao longo do artigo. Mas, num país com extensão territorial como a do Brasil e tamanha diversidade sociocultural há possibilidade de políticas 
municipais ou estaduais se efetivarem de maneira mais ordenada, para o alcance dos objetivos propostos.

De qualquer forma, o que está bastante claro a partir das reflexões realizadas neste artigo é que o potencial existente é de grande dimensão e se encontra "reprimido", uma vez que falta ainda qualificação profissional nas várias áreas para atuação com o lazer. E que esse quadro também depende de políticas setoriais com essa finalidade, no lazer, na educação superior em cursos de licenciaturas e cursos de bacharelados, de forma suficientemente adequada para as urgentes necessidades sociais das crianças, adolescentes e jovens brasileiros direcionarem melhor suas vidas, seus gostos, aptidões e sentidos.

\section{Referências Bibliográficas}

BRASIL, (2002). Constituição da República Federativa do Brasil: promulgada em 5 de outubro de 1988. Obra Coletiva da Editora Saraiva com a colaboração de Antonio Luiz de Toledo Pinto, Márcia Cristina Vàz dos Santos e Lívia Céspedes. São Paulo: Saraiva.

DUMAZEDIER, Jofre (1980). Valores e conteúdos culturais do lazer. São Paulo: SESC.

FERREIRA, Marcelo Pereira de Almeida; MARCELLINO, Nelson Carvalho,_(Org.) (2007). Brincar, Jogar, Viver: Programa esporte e lazer da cidade. Volume 1, n. 1, Brasília: Ministério do Esporte/Editora Total.

FROMM, Eric (1963). Psicanálise da sociedade contemporânea. Rio de Janeiro: Zahar.

MARCELLINO, Nelson Carvalho (2000). Lazer e educação. Campinas: Papirus.

MARCELLINO, Nelson Carvalho (2002). Estudos do lazer: uma introdução. Campinas: Autores Associados.

MARCELlinO, Nelson Carvalho (Org.) (2008). Políticas públicas de lazer. Campinas: Editora Alínea, (Coleção estudos do lazer). 
PINTO, Leila Mirtes Santos de Magalhães (2008). Políticas públicas de lazer no Brasil: uma história a contar. In: MARCELLINO, Nelson Carvalho (Org.). Políticas públicas de lazer. Campinas: Alínea. (Coleção estudos do lazer).

\section{Autores}

José Carlos de Almeida Moreno, Faculdades Integradas Fafibe, São Paulo Brasil - Grupo de Estudos em Preparação Profissional - GEPPEF UNICAMP e Núcleo de Estudos em Preparação Profissional em Educação Física - NEPPEF- UNESP.

Contato: profcacau@ig.com.br

Luciene Ferreira da Silva, - Universidade Estadual Júlio de Mesquita Filhọ - UNESP, São Paulo - Brasil - Grupo de Pesquisa em Lazer- GPLUNIMEP, Grupo de Estudos em Preparação Profissional - GEPPEFUNICAMP e Núcleo de Estudos em Preparação Profissional em Educação Física -NEPPEF - UNESP.

Contato: lucienebtos@ig.com.br luciene@fc.unesp.br

\section{Como citar este artigo:}

MORENO, José Carlos de Almeida e SILVA, Luciene Ferreira da. Lazer, educação e políticas públicas em países emergentes: reflexões sobre o caso brasileiro. Revista ACOALFAplp: Acolhendo a Alfabetização nos Países de Língua portuguesa, São Paulo, ano 4, n. 7, 2009. Disponível em: <http://www.acoalfaplp.net>. Publicado em: setembro 2009.

Recebido em outubro de 2008./ Aprovado em dezembro de 2008. 